\title{
Increase of pullout strength of spinal pedicle screws with conical core: biomechanical tests and finite element analyses
}

\author{
Ching-Chi Hsu ${ }^{\text {a }}$, Ching-Kong Chao ${ }^{\text {a }}$, Jaw-Lin Wang ${ }^{\mathrm{b}}$, Sheng-Mou Hou ${ }^{\mathrm{b}}$, \\ Ying-Tsung Tsai ${ }^{\text {a }}$, Jinn Lin ${ }^{\mathrm{b}, *}$ \\ ${ }^{a}$ Department of Mechanical Engineering, National Taiwan University of Science and Technology, Taipei 106. Taiwan \\ ${ }^{b}$ Department of Orthopedic Surgery, National Taiwan University Hospital, No. 7 Chung Shan S. Rd. Taipei 100, Taiwan
}

\begin{abstract}
Screw loosening can threaten pedicle screw fixation of the spine. Conical screws can improve the bending strength, but studies of their pullout strength as compared with that of cylindrical screws have shown wide variation. In the present study, polyurethane foam with two different densities $\left(0.32\right.$ and $\left.0.16 \mathrm{gm} / \mathrm{cm}^{3}\right)$ was used to compare the pullout strength and stripping torque among three kinds of pedicle screws with different degrees of core tapering. Three-dimensional finite element models were also developed to compare the structural performance of these screws and to predict their pullout strength. In the mechanical tests, pullout strength was consistently higher in the higher density foam and was closely related to screw insertion torque $(r=0.87$ and 0.81 for the high and low density foam, respectively) and stripping torque ( $r=0.92$ and 0.78 , respectively). Conical core screws with effective foam compaction had significantly higher pullout strength and insertion torque than cylindrical core screws $(p<0.05)$. The results of finite element analyses were closely related to those of the mechanical tests in both situations with or without foam compaction. This study led to three conclusions: polyurethane foam bone yielded consistent experimental results; screws with a conical core could significantly increase pullout strength and insertion torque over cylindrical; and finite element models could reliably reflect the results of mechanical tests.

(c) 2004 Orthopaedic Research Society. Published by Elsevier Ltd. All rights reserved.
\end{abstract}

Keywords: Pedicle screw; Pullout strength; Pullout test; Finite element analysis

\section{Introduction}

Pedicle screw fixation, widely used for different thoracolumbar spinal disorders, has the advantage of rigid fixation with minimal fused segments [20]. Fixation failures still occur, however, and may jeopardize the spinal alignment and fixation stability and lead to severe complications. As reported in the literature, the incidence of screw loosening ranges from $0.6 \%$ to $11 \%[17]$ and might be even higher in osteoporotic spines [14]. The pullout strength of pedicle screws is mainly determined by screw

\footnotetext{
Corresponding author. Tel.: +886223123456x5278; fax: +8862 23224112.

E-mail address: jin@ha.mc.ntu.edu.tw (J. Lin).
}

design $[13,16]$, which includes outer and core diameters, pitches, and thread profiles. Modification of the screw design can substantially affect the pullout strength. Recently, conical screws with tapering of the core diameter have been introduced to increase the bending strength of the screws $[1,14]$. However, their pullout strengths as compared with that of cylindrical screws have varied widely $[1,8,14,15,18]$. High variation of the cadaver bone quality and pedicle structures, insufficient sample size, and incomparable screw structures are responsible for the discrepancy and may lead to biased study results and invalid conclusions in spite of careful study design $[12,13]$.

In the present study, screw pullout and stripping tests were conducted according to an American Society for 
Testing and Materials (ASTM) standard [3] on three kinds of commercially available spinal pedicle screws with different degrees of core tapering. Polyurethane foam was used to simulate cancellous bone but yet provide more uniform material properties. Concurrently, three-dimensional finite element models of these pedicle screws were created to simulate the mechanical tests. We hypothesized that conical screws could produce foam compaction during screw insertion and yield higher insertion torques and pullout strengths. Furthermore, we hoped to demonstrate that finite element analyses could effectively predict the results of mechanical experiments.

\section{Materials and methods}

\section{Pedicle screws}

Three kinds of commercially available pedicle screws were studied: Cotrel-Dubousset (CD) (Medtronic Sofamor-Danek, Memphis, TN), Texas Scottish Rite Hospital (TSRH) (Danek, Memphis, TN), and Moss Miami (DePuy Spine, Raynham, MA). For application to different levels of vertebrae, each kind of pedicle screw had three different sizes (Fig. 1), which were designated as type I, II, and III (from large to small outer diameter). Consequently, nine distinct types of pedicle screws were tested. The pertinent dimensions of these screws included outer diameter, core diameter, pitch, proximal half angle, distal half angle, proximal root radius, distal root radius, thread width, conical angle, and the beginning point of the conical angle (Table 1) and were measured by means of an optical comparator (Starrett HF-600, Unlimited Services, New Haven, MI). All screws were made of a titanium alloy and were $45 \mathrm{~mm}$ long. CD screws had a cylindrical outer diameter and conical core diameter with a conical angle of $4^{\circ}$. TSRH screws also had a cylindrical outer diameter and conical core diameter, but the conical part was shorter than that of CD screws. The beginning point of the conical angle differed between these two screws. Moss Miami screws had cylindrical outer and core diameters.

\section{Mechanical tests}

We used cellular polyurethane foam (Pacific Research Lab., Vashon, WA) conforming to ASTM standard F1839-97 [2] to prevent the wide individual variation of the mechanical properties of cadaver bones encountered in biomechanical tests. Two densities of the foam, 0.32 and $0.16 \mathrm{gm} / \mathrm{cm}^{3}$ with a compressive modulus of 137.5 and $23 \mathrm{MPa}$, a compressive strength of 5.4 and $2.3 \mathrm{MPa}$, and a porosity of $71 \%$ and $86 \%$, respectively, were used. Each brick of foam bone $(13 \mathrm{~cm} \times 18 \mathrm{~cm} \times 4 \mathrm{~cm})$ was equally divided into nine blocks for study of the nine screws. To decrease the bias caused by size discrepancy between core diameter and pilot hole, the foam blocks were pre-drilled using straight drill bits with a diameter of $0.2 \mathrm{~mm}$ less than the core diameter of the screws. Then the pedicle screws were inserted without pre-tapping. Under this condition, the conical core of screws could compact the foam during screw insertion. For a fair comparison, the length of the threaded part that purchased on the foam was kept constant: $35 \mathrm{~mm}$ for all screws. Because of the different lengths of the unthreaded tip among the different screws, the total length of the screw inserted in the foam block varied from $38 \mathrm{~mm}$ to $44 \mathrm{~mm}$.
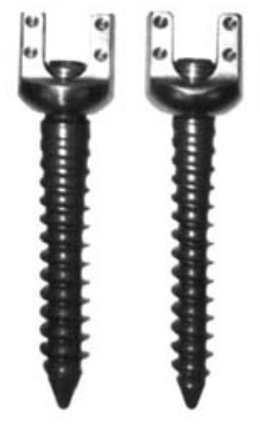

CD
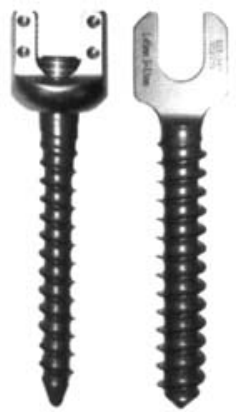

TSRH
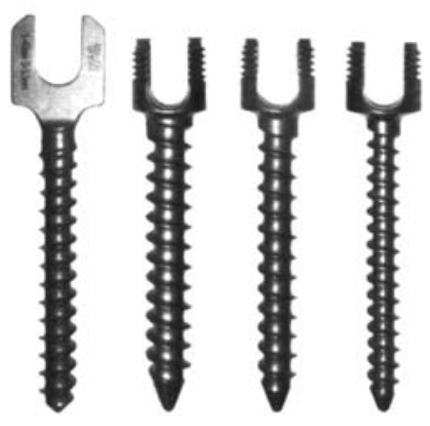

Moss Miami

Fig. 1. Three different pedicle screws tested in this study. Each had three types-I, II, and III-corresponding to different outer diameters.

Table 1

Dimensions of the pedicle screws

\begin{tabular}{|c|c|c|c|c|c|c|c|c|c|c|}
\hline & $\begin{array}{l}\text { Outer } \\
\text { diameter } \\
(\mathrm{mm})\end{array}$ & $\begin{array}{l}\text { Core } \\
\text { diameter } \\
(\mathrm{mm})\end{array}$ & $\begin{array}{l}\text { Pitch } \\
(\mathrm{mm})\end{array}$ & $\begin{array}{l}\text { Proximal root } \\
\text { radius (mm) }\end{array}$ & $\begin{array}{l}\text { Distal root } \\
\text { radius (mm) }\end{array}$ & $\begin{array}{l}\text { Proximal } \\
\text { half } \\
\text { angle }\left(^{\circ}\right)\end{array}$ & $\begin{array}{l}\text { Distal half } \\
\text { angle }\left(^{\circ}\right)\end{array}$ & $\begin{array}{l}\text { Thread } \\
\text { width } \\
\text { (mm) }\end{array}$ & $\begin{array}{l}\text { Conical } \\
\text { angle }\left({ }^{\circ}\right)\end{array}$ & $\begin{array}{l}\text { Beginning } \\
\text { point of } \\
\text { conical angle } \\
(\mathrm{mm})\end{array}$ \\
\hline CD II & 6.50 & 4.10 & 2.8 & 0.88 & 1.20 & 23.50 & 9.67 & 0.20 & 4 & 28 \\
\hline CD III & 5.50 & 3.84 & 2.71 & 0.81 & 1.23 & 21.50 & 10.33 & 0.10 & 4 & 31.17 \\
\hline TSRH I & 7.50 & 4.98 & 2.8 & 0.83 & 1.16 & 21.33 & 5.33 & 0.18 & 4 & 35 \\
\hline Moss Miami I & 6.90 & 4.5 & 2.98 & 3.31 & 3.31 & 29.83 & 28.50 & 0.18 & - & - \\
\hline Moss Miami II & 5.85 & 4.19 & 2.94 & 3.31 & 3.31 & 30 & 27.83 & 0.19 & - & - \\
\hline Moss Miami III & 4.87 & 3.03 & 2.48 & 2.54 & 2.54 & 33.17 & 27.67 & 0.19 & - & - \\
\hline
\end{tabular}




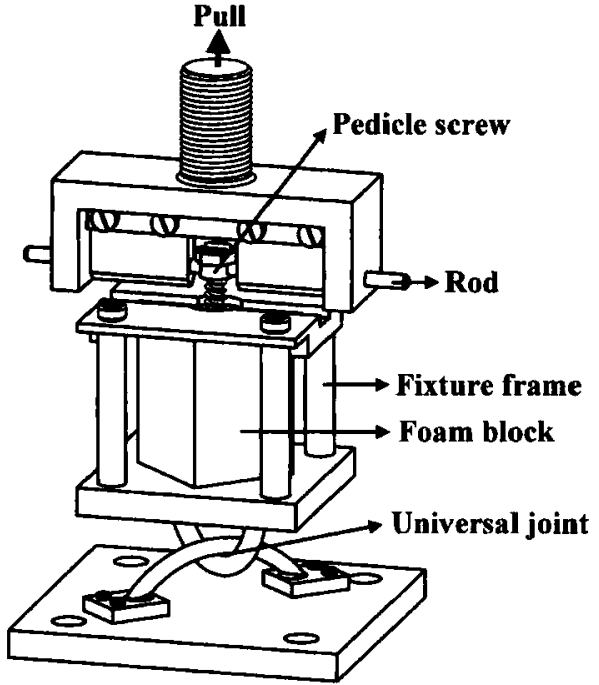

Fig. 2. Setup for pullout tests.

The foam block was placed in a fixture frame whose top surface had a spherical hole for the screw head. The foam block was completely seated in the fixture frame when an axial load was applied via a custom-machined rod tightly fastened to the screw head (Fig. 2). Following ASTM standard F1691-96 [3], the testing setup had a universal joint linked to the base plate of the MTS servohydraulic testing machine (Bionix 858, MTS Corp., Minneapolis, MN) to ensure the applied load was aligned with the screw's longitudinal axis. The screws were extracted at a loading rate of $5 \mathrm{~mm} / \mathrm{min}$, and the load-displacement curves were recorded (Fig. 3A) with a data acquisition system (instruNet, GW Instruments, Somerville, MA). The peak load to pull out the screws was defined as the pullout strength. The pullout tests were then repeated using tapered drill bits with a structure similar to the core of the conical screws to investigate the condition without foam compaction.

Next, screw-stripping tests were performed with pedicle screws inserted into new foam blocks pre-drilled with straight drill bits. The insertion torque was continuously monitored by a torsional load cell on the MTS system. To avoid exerting axial force on the screws, screws were driven by applying a horizontal force manually to the rod fastened to the screw head at a speed of two rpm. The torque-turn curves were recorded (Fig. 3B). To ensure a constant length of the threaded part inserted in the foam block, metal shims with different thicknesses were placed between the foam block and screw head.

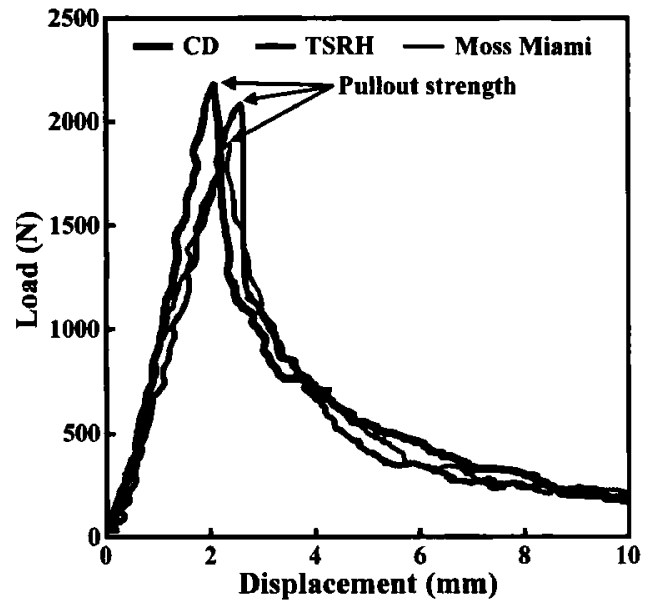

A
Initially, as the screws were inserted, the insertion torque increased gradually. When the length of the inserted threaded part reached $35 \mathrm{~mm}$, the screw head collided with the shims and the insertion torque rose quickly. As the screws were further advanced, the insertion torque reached a maximum and then dropped abruptly when the foam was stripped. The highest torque before the screw head collided with the shims was defined as the maximal insertion torque. The highest torque to strip the foam was defined as the stripping torque. Increase of the insertion torque was defined as the difference between the maximal insertion torque and initial insertion torque. The pullout tests and screw stripping tests were performed on six of each screw type.

Finite element analysis

The finite element analyses of the pedicle screws were conducted using commercial software ANSYS 5.7 (Canonsburg, PA). The screw models were built to the measured geometry and dimensions. Surface models were first generated by helical sweep of a pre-determined thread with Ansys Parametric Design Language. Then the surface models were transformed to three-dimensional models by subtraction from a solid cylinder with the use of a Boolean operation. The screws were assumed inserted in the center of a cylinder of cancellous bone with a diameter of $30 \mathrm{~mm}$ (Fig. 4). The material properties of the screws and bone were assumed to be linear isotropic. The elastic modulus was $114 \mathrm{GPa}$ for pedicle screws and 137.5 or $23 \mathrm{MPa}$ for bone like

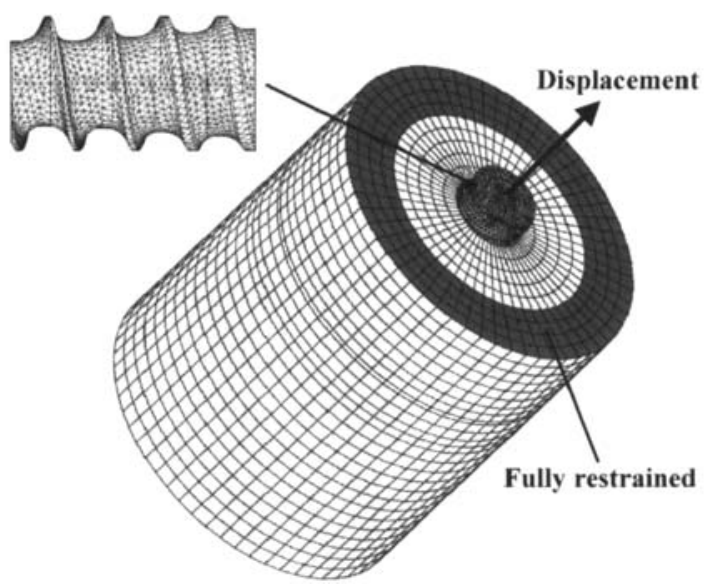

Fig. 4. Finite element model. The gray zone was fully constrained.

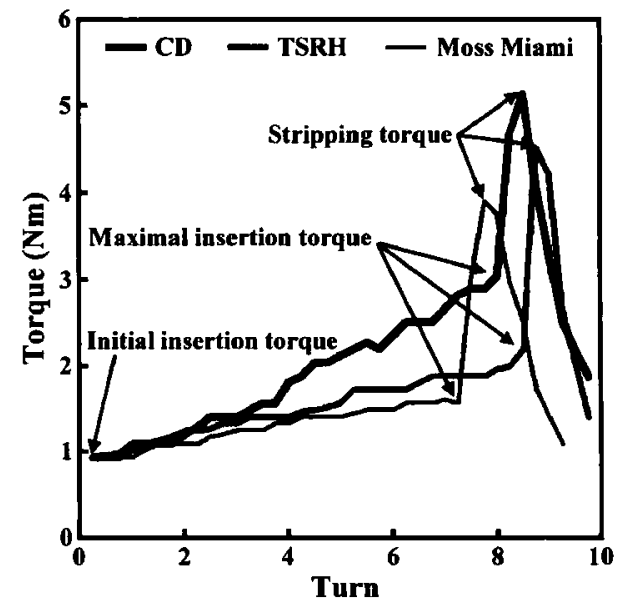

B

Fig. 3. (A) The load-displacement curve from pullout tests of the three screws. (B) The torque-turn curve from stripping tests of the three screws. 
the foams used in the biomechanical tests; Poisson's ratio was 0.3 for both screws and bone. The screws and bones were map-meshed, with the exception of the irregular contact areas, which were free-meshed.

The elements used were high order 20-node brick elements of SOLID 95. Contact elements were applied to the interface between the pedicle screw and bone. The surface of the pedicle screw was meshed with the elements of CONTA 174, and the surface of bone was meshed with elements of TARGE 170 . The frictional coefficient was set to zero. The loading condition was an axial displacement of $0.01 \mathrm{~mm}$ applied to the end surface of the pedicle screw, and the screw could be displaced only in the axial direction. The boundary condition was full constraint at the surface of the bone end to simulate the experimental condition (Fig. 4).

The total number of elements in the models ranged from 110,000 to 220,000 ; the total number of nodes ranged from 210,000 to 410,000 . The computer solution time ranged from 12 to $28 \mathrm{~h}$. The solution was achieved by the Precondition Conjugate Gradient solver with small deformation. Numerical instability was checked by decreasing the element size; the solutions were considered converged when the variation of the sequential analytic results was less than $3 \%$. For screws with a conical core, the foam compaction effects were simulated by adjusting the elastic modulus of the bone surrounding the conical core according to the density change of the bone around that core. The elastic modulus of bone was assumed to be a function of the density squared. Density change was calculated on the basis of the volume reduction caused by the conical core. In postprocessing analysis, the bone-screw interface stiffness was assessed by analyzing the total reaction force on screws and the total strain energy of bones. The total reaction force was defined as the summation of the resultant axial force on the nodes over the end surface of the screw with pre-applied displacement. The total strain energy was defined as the summation of the strain energy of all the bone elements. The results of mechanical tests and finite element analyses were compared by analysis of variance and linear regression test. Significance was defined as $p<0.05$.

\section{Results}

In pullout tests, screw displacement at the point of peak load was less than $2 \mathrm{~mm}$ in all the screws. In stripping tests, foam bone was stripped within one turn after the screw head collided with the shim. In both tests, the failure was cylindrical shear of the polyurethane foam surrounding the screws, and the screw structure was completely preserved. The pullout strength, insertion torque, and stripping torque were consistently higher in the foam bones with the higher density (Table 2). Among the nine screw types, pullout strength was significantly related to stripping torque, $r=0.92$ and 0.78 for the 0.32 and $0.16 \mathrm{gm} / \mathrm{cm}^{3}$ foams, respectively. The $\max -$ imal insertion torque was also significantly related to the pullout strength $(r=0.87$ and 0.81 for the higher and lower density foams, respectively) and the stripping torque $(r=0.89$ and 0.87 for the higher and lower density foams, respectively). For conical screws, the pullout strength was significantly higher in situations with foam compaction than in situations without foam compaction ( $p<0.05$ for both higher and lower density foams). The average increase of pullout strength for CD and TSRH screws was $16.3 \%$ and $6.8 \%$ in foams with a density of $0.32 \mathrm{gm} / \mathrm{cm}^{3}$ and was $9.8 \%$ and $6.4 \%$ in foams with a density of $0.16 \mathrm{gm} / \mathrm{cm}^{3}$. With foam compaction, conical screws also had a significantly higher pullout strength, maximal insertion torque, and increase of insertion tor- que than did cylindrical screws by an analysis of variance test $(p<0.05$ for both foams).

In the finite element analysis, a strong relationship between the total reaction force and total strain energy was found ( $r=0.99$ for both foam bones). Screw deformation was minimal $(<0.1 \%)$, compatible with the findings in the mechanical tests. The bone-screw interface stiffness was closely related to the strength measured in the pullout tests for $\mathrm{CD}(r=0.95$ and 0.91 for the higher and lower density foams, respectively, in situations without foam compaction; $r=0.98$ and 0.92 in situations with foam compaction), TSRH ( $r=0.95$ and 0.86 in situations without foam compaction; $r=0.93$ and 0.77 in situations with foam compaction), and Moss-Miami $(r=0.88$ and 0.58$)$. The screws with a larger outer diameter had higher bone-screw interface stiffnesses and pullout strengths. When the nine screws were considered together, the relationship was still close $(r=0.85$ vs. 0.59 in situations without foam compaction; $r=0.90$ vs. 0.77 in situations with foam compaction). The bone-screw interface stiffness was also higher in situations with foam compaction, especially in CD screws with a long conical core.

\section{Discussion}

Pullout strength of pedicle screws has been extensively studied using cadaver bone $[5,7,18,21]$, animal bone $[1,9,11,15]$, and artificial materials $[5,8,9,11]$ by either axial pullout or cephalocaudad toggling tests. Straight axial pullout of the pedicle screws, although not the only mechanism responsible for clinical failure, is a popular experimental testing mode and has generally been accepted for evaluation of screw-bone interface strength of pedicle screws in different conditions $[1,14,18]$. This method provides a standard test to check the uniformity of the screws and to compare the pullout strength of different screw designs [3]. The pullout strength of pedicle screws might be affected by design, bone quality, pedicle structures, inserted length, and the size of pilot holes. For a fair comparison among different screws, adequate control of these variables is crucial.

A conical screw design was originally intended to increase the strength of the pedicle screw by decreasing the stress concentration effects caused by the sharp geometrical change at the thread-shaft junction. Theoretically, the conical core could compact its neighboring cancellous bone in the pedicle and increase the screw insertion torque and pullout strength $[1,14]$. However, reports of the pullout strength of conical screws as compared with that of the conventional cylindrical screw vary markedly. For example, Kwok et al. [14] reported that conical screws yielded higher insertion torque than cylindrical screws, but their pullout strength did not significantly 


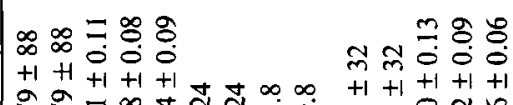

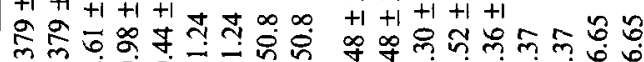

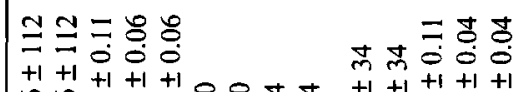

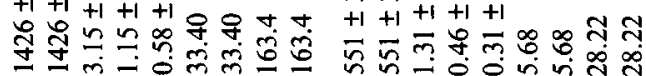

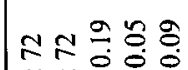

$\frac{20}{0}=$

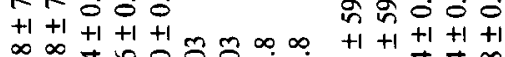

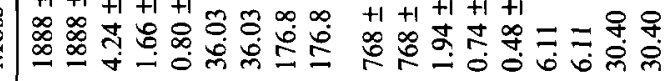

$\Xi 5 \%=ㅇ$

$+1+1++1+100 \quad n=0$

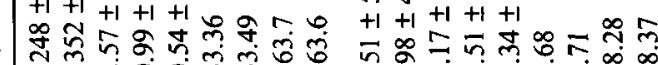

- iosmm- in

$=\sqrt{\mathrm{N}} \mathrm{\Xi}=\frac{0}{0}$

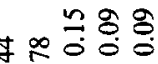

卷

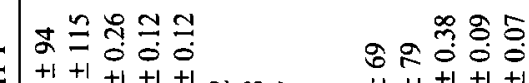

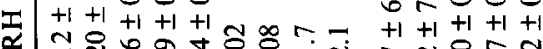

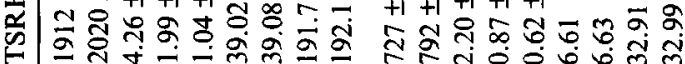

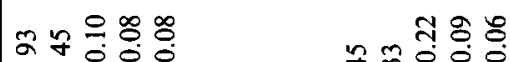

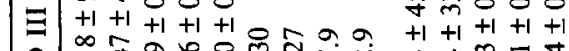

\&

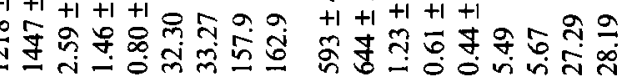

$=58$

$3=000$

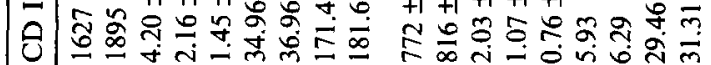

$-\overline{0} \pi \simeq$

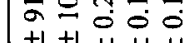

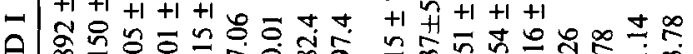

(1)

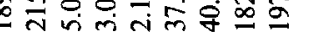

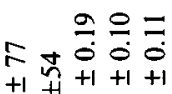

ำ

实

目望

菏

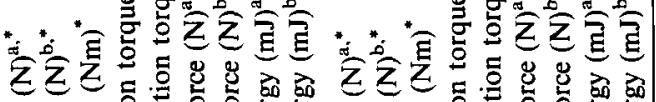

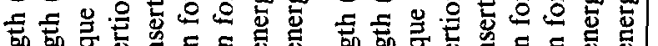

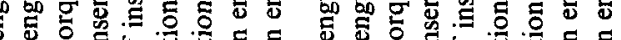

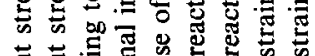

苛言.

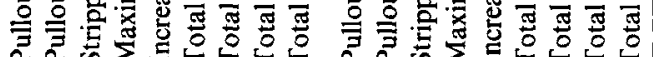


differ. Abshire et al. [1] and Ono et al. [18] found conical screws had higher pullout strength than cylindrical screws with similar thread design and pitch. Choi et al. [8] reported that conical screws were consistently more effective against pullout than cylindrical screws, especially when the outer diameter of the screws was kept straight. By contrast, Lill et al. [15] found the pullout strength of the conical screws, especially after cyclic loading, was less than that of cylindrical screws. These contradictory results might be attributed to variations in bone quality, screw-cortical purchase, and screw dimensions responsible for bone purchase.

We used foam with more consistent properties in an attempt to prevent the bias caused by variation of bone quality, pedicle structures or different screw-cortical purchase. The foam was also readily availability, easy to handle, and did not degrade during testing. Incomparability of screw dimensions may lead to biased results from comparisons of pullout strength of conical and cylindrical screws and should be examined before experiments are started $[1,18]$.

In the mechanical tests, pullout strength was closely related to the stripping torque because of the similar shear failure mechanism [16]. Both tests reliably assess the risk of screw loosening. The pullout strength and insertion torque in the foam with the higher density was consistently higher than that in the foam with the lower density. This result supports findings that pullout strength or insertion torque was higher in bone with higher bone mineral density $[9,15,18]$. The pullout strength of conical screws was significantly higher in situations with foam compaction. The conical core could effectively compact the foam during screw insertion and yield higher pullout strength. Conical screws also had a significantly higher maximal insertion torque and greater increase of insertion torque during screw insertion than did cylindrical screws. The conical core advancing through the bone acted like the screw head that was colliding with the bone and led to higher insertion torques and greater increases in insertion torque.

Another controversial question is the relationship between screw insertion torque and pullout strength. The factors that affect screw insertion torque include screw design, the shear strength of the surrounding bone, friction between the screw and the bone, and the size of the pilot hole. Most studies have demonstrated a close relationship between pullout strength and maximal insertion torque $[9,15,18,21]$. However, in the study of Kwok et al. [14], the insertion torque was not consistently related to pullout strength. In the study of Okuyama [17], the insertion torque did not significantly differ between patients with and without loosening of the pedicle screws. In the present study, the maximal insertion torque was consistently and closely related to the density of the foam and the pullout strength of the screws. As shown in the torque-turn curves (Fig. 3B), the screw insertion torque increased sharply when the screw head collided with the shim. We postulate that variation of choosing the points with maximal insertion torque might be one of the factors causing inconsistent results.

The finite element method can save the expense, time, and effort of repeated mechanical tests. The models can incorporate all the screw design factors that potentially affect the pullout strength. Sensitivity analysis can further investigate the effects of an individual design factor independently. The linear relationship between total strain energy and total reaction force was compatible with the linear part of the load-displacement curve in the pullout tests. The results of finite element analyses were closely related to those of mechanical tests in situations both with and without foam compaction. The finite element model can be used to assess the structural comparability and the effects of foam compaction among different screw designs without the necessity of mechanical tests.

The present study has potential limitations. First, the applicability of experimental results based on the polyurethane foam to real clinical conditions is a concern. Use of polyurethane foam to simulate clinical conditions is supported by two facts: $81 \%$ of the vertebral bone in men and $71 \%$ in women is cancellous [10], and pedicle screws principally anchor on cancellous bone. Moreover, the material properties of the polyurethane foam are on the same order of human vertebral cancellous bone, which has a density ranging from 0.09 to 0.34 $\mathrm{g} / \mathrm{cm}^{3}$, a compressive modulus ranging from 127 to $725 \mathrm{MPa}$, and a compressive strength ranging from 0.60 to $6.17 \mathrm{MPa}$ [4]. The pullout strength in the foam with a density of $0.16 \mathrm{gm} / \mathrm{cm}^{3}$ was close to that of the study of Kwok et al. using osteoporotic vertebrae [14]. The polyurethane foam can avoid the material and structural bias and be a standard test material for comparative studies among different screw designs [2]. In this study, because the size and distribution of foam cells were more heterogeneous in the foam with the lower density, testing results had wider standard deviations and poorer relationship to finite element results than those of the higher density foam. However, these standard deviations were still much smaller than the 30\%$40 \%$ reported for human cadaver bones [19].

A second limitation of the study is that the absolute values of the results were subject to changes of material properties, interface conditions, boundary conditions, and loading conditions. Nevertheless, these values mainly reflected the relative scales or the trend in different screw designs and were useful especially for comparative studies $[6,16]$. Another limitation is that modification of the foam modulus around the conical core of the screws seems subjective, but this simple action allowed us to correctly simulate the conditions of mechanical tests in the finite element analyses. Further verification of this method is necessary. 
In conclusion, pullout tests and stripping tests of pedicle screws using polyurethane foam yielded consistent experimental results. A higher foam density consistently yielded a higher pullout strength and screw insertion torque. Conical core screws demonstrated higher pullout strength and screw insertion torque than cylindrical core screws with comparable geometries. The maximal insertion torque was closely related to pullout strength, if correctly measured. Finite element analyses used in this study could reliably reflect the results of mechanical tests.

\section{References}

[1] Abshire BB, McLain RF, Valdevit A, Kambic HE. Characteristics of pullout failure in conical and cylindrical pedicle screws after full insertion and back-out. Spine $J$ 2001;1:408-14.

[2] Allen RF, Baldini NC, Donofrio PE, Gutman EL, Keefe E, Kramer JG. Standard specification for rigid polyurethane foam for use as a standard material for testing orthopedic devices and instruments (F1839-97). Annual book of ASTM standards, medical devices and services. West Conshohocken, The American Society for Testing and Materials, 1998.

[3] Allen RF, Baldini NC, Donofrio PE, Gutman EL, Keefe E, Kramer JG. Standard test method for determining axial pull-out strength of medical bone screws (F1691-96). Annual book of ASTM standards, medical devices and services. West Conshohocken, The American Society for Testing and Materials, 1998.

[4] Banse X, Sims TJ, Bailey AJ. Mechanical properties of adult vertebral cancellous bone: correlation with collagen intermolecular cross-links. J Bone Miner Res 2002;17:1621-8.

[5] Barber JW, Boden SD, Ganey T, Hutton WC. Biomechanical study of lumbar pedicle screws: Does convergence affect axial pullout strength?. J Spinal Disord 1998;11:215-20.

[6] Brown GA, McCarthy T, Bourgeault CA, Callahan DJ. Mechanical performance of standard and cannulated $4.0-\mathrm{mm}$ cancellous bone screws. J Orthop Res 2000;18:307-12.

[7] Buhler DW, Berlemann U, Oxland TR, Nolte LP. Moments and forces during pedicle screw insertion: in vitro and in vivo measurements. Spine 1998;23:1220-8.

[8] Choi W, Lee S, Kim JW, Kim JK, Goel V. Assessment of pullout strength of various pedicle screw designs in relation to the changes in bone mineral density. In: 48th Annual Meeting of the Orthopaedic Research Society, 2002.

[9] Daftari TK, Horton WC, Hutton WC. Correlations between screw hole preparation, torque of insertion, and pullout strength for spinal screws. J Spinal Disord 1994;7:139-45.

[10] Eastell R, Mosekilde L, Hodgson SF, Riggs BL. Proportion of human vertebral body bone that is cancellous. J Bone Miner Res 1990;5:1237-41.

[11] Gausepohl T, Mohring R, Penning D, Koebke J. Fine thread versus coarse thread: a comparison of the maximum holding power. Injury 2001;32:SD1-7.

[12] George DC, Krag MH, Johnson CC, Vanhal ME, Haugh LD, Grobler LJ. Hole preparation techniques for transpedicle screws: effect on pull-out strength from human cadaveric vertebrae. Spine 1991;16:181-4.

[13] Krag MH, Beynnon BD, Pope MH, Frymoyer JW, Haugh LD, Weaver DL. An internal fixation for posterior application to short segments of the thoracic, lumbar, or lumbosacral spine: design and testing. Clin Orthop 1986;203:75-98.

[14] Kwok AWL, Finkelstein JA, Woodside T, Hearn TC, Hu RW. Insertional torque and pull-out strengths of conical and cylindrical pedicle screws in cadaveric bone. Spine 1996;21: 2429-34.

[15] Lill CA, Schlegel U, Wahl D, Schneider E. Comparison of the in vitro holding strengths of conical and cylindrical pedicle screws in a fully inserted setting and backed out 180 degrees. J Spinal Disord 2000;13:259-66.

[16] Lin J, Lin SJ, Chiang H, Hou SM. Bending strength and holding power of tibial locking screws. Clin Orthop 2001;385: 199-206.

[17] Okuyama K, Abe E, Suzuki T, Tamura Y, Chiba M, Sato K. Can insertion torque predict screw loosening and related failures? An in vivo study of pedicle screw fixation augmenting posterior lumbar interbody fusion. Spine 2000;25:858-64.

[18] Ono A, Brown MD, Latta LL, Milne EL, Holmes DC. Triangulated pedicle screw construct technique and pull-out strength of conical and cylindrical screws. J Spinal Disord 2001;14:323-9.

[19] Shepard MF, Wang JC, Oshtory R, Yoo J, Kabo JM. Enhancement of pedicle screw fixation through washers. Clin Orthop 2002;395:249-54.

[20] Zdeblick TA. A prospective, randomized study of lumbar fusion: preliminary results. Spine 1993;18:983-91.

[21] Zdeblick TA, Kunz DN, Cooke ME, McCabe R. Pedicle screw pullout strength: correlation with insertional torque. Spine 1993; 18:1673-6. 